\title{
DEMOCRACIA COSMOPOLITA: déficits conceituais e equívocos políticos*
}

\section{Sérgio Costa}

Früber wurden in Revolutionen Babnhöfe besetzt, heute besetzen wir Begriffe [Antigamente, nas revoluções, as estações de trem eram ocupadas, hoje ocupamos conceitos].

Heiner Geißler ${ }^{1}$

As duras feridas na ordem mundial abertas pelo ataque terrorista aos Estados Unidos ainda levarão muito tempo para se cicatrizar. A bem da verdade, os movimentos mais recentes e a guerra

* Versões anteriores desse trabalho foram apresentadas em workshop em Florianópolis em outubro de 2002 e, em seguida, no XXV Encontro da Anpocs. Agradeço as criticas e sugestões recebidas nessas ocasiões. A responsabilidade pelas deficiências remanescentes é, naturalmente, minha.

Artigo recebido em outubro/2002

Aprovado em abril/2003 dos Estados Unidos e da Inglaterra ao Iraque aprofundam as ameaças de ruptura do frágil consenso em favor da manutenção da paz, criando um fosso intransponível entre povos e culturas.

Se no plano político, o cenário é sombrio, o dano observado entre correntes que vinham se transformando no mainstream da teoria política contemporânea não foi menor. Trata-se aqui dos diferentes aportes que, fraseando suas teses de formas diversas, convergiam em apontar a confluência para uma paz duradoura nos termos de uma ordem mundial cosmopolita. Os acontecimentos recentes trouxeram à tona a evidência de que as teorias da democracia cosmopolita se equilibram, analiticamente, sobre um conjunto frágil de conceitos. Politicamente, seu motor é um wishful thinking, levado ao paroxismo, que transforma o imperativo categórico da ordem cosmopolita em materialidade empírica e o dever ser da 
justiça além fronteiras no ser generalizado de pessoas e Estados nacionais altruístas.

Em sua vertente mais explícita, a defesa da democracia cosmopolita proclamou, no âmbito do paradigma da modernização reflexiva, a completude do projeto moderno. Para autores como Giddens (2000) e Beck (1999, p. 319), "a jaula da modernidade se abriu", libertando-se dela o espírito reflexivo que governaria o mundo sob a égide de uma ética universal. ${ }^{2}$

A tese da democracia cosmopolita recebeu, desde os anos de 1990, formulações muito diversas e não faria jus à abrangência e à complexidade desses diferentes aportes, resumi-los e descartá-los, genericamente, desconsiderando seus nexos internos e as diferenças que os separa. No âmbito deste artigo, o percurso seguido será outro. Primeiro, procurar-se-á delinear, brevemente, os contornos mínimos do projeto ou dos projetos teóricos da democracia cosmopolita. Em seguida, tomam-se dois elementos recorrentes nas diferentes contribuições, a saber, a aposta numa "sociedade civil mundial" e numa ética universal dos direitos humanos. A intenção é mostrar como as formulações assentam-se sobre uma premissa problemática: conferese, em ambos os casos, implícita ou explicitamente uma anterioridade ontológica e histórica às chamadas sociedades do Atlântico Norte na produção da ordem cosmopolita, como se estas detivessem o monopólio de produção dos ingredientes considerados básicos para a democracia mundial, tese que é, empiricamente, infundada e, politicamente, inoportuna.

\section{Democracia cosmopolita: contornos mínimos}

O temor e a suspeita, presentes até muito recentemente entre vários autores e lideranças políticas, de que a alusão à necessidade de relativizar o princípio da soberania nacional em favor de uma visão transnacional da política constituía, na verdade, um mero estratagema ideológico para justificar novas formas de imperialismo, parecem finalmente dissipados. Assim, são, afortunadamente, poucos os que seguem acreditando que o apelo a uma po- lítica global dos direitos humanos ou a uma política mundial para o meio ambiente representa uma armadilha retórica, criada no bojo das relações de poder Norte/Sul, com o propósito de manter e legitimar o jogo desigual de exploração dos países pobres pelos ricos. Entendeu-se que, a despeito de possíveis instrumentalizações ideológicas, as transformações efetivas ocorridas levaram à necessidade de uma revisão da chamada Paz de Westfália, que consolidou, no século XVII, a ordem dos Estados-Nação (ver McGrew, 1997).

Trata-se aqui de um feixe de processos simultâneos que atingem de forma variável, mas inevitável, todos os grupos demográficos em todas as regiões do mundo e nos diferentes campos da topografia social.

$\mathrm{Na}$ esfera da economia, sabe-se que a interpenetração das diversas partes do mundo remonta à descoberta da América - ou é até mais antiga do que esta, a depender da perspectiva adotada. Igualmente conhecidos são os números vigorosos do comércio e dos fluxos financeiros internacionais observados já na virada para o século XX, concomitante à chamada pax britannica. Entretanto, nos anos recentes, configurou-se, pela primeira vez, aquilo que pode ser denominado uma economia mundial, conceito que tem um sentido preciso: significa não apenas que os diferentes países intercambiam produtos, serviços e capitais, mas que o conjunto da superfície terrestre, excetuadas muito poucas regiões, tornou-se uma plataforma da acumulação e reprodução capitalista, não apenas em seu sentido financeiro, mas também naquilo que concerne ao capital produtivo. Isso significa que, para os cálculos locacionais, as fronteiras dos Estados-Nação perderam sua relevância, o que conta é apenas o trade-off risco/remuneração observado nas diferentes possibilidades de investimento. Com isso, o Estado-Nação não perde inteiramente sua função reguladora sobre a economia, afinal continua mantendo o controle sobre um fator que, a despeito de todas as inovações, ainda é decisivo para a produção de bens e serviços, a saber, o trabalho. No mínimo, o Estado mostra-se, portanto, presente ao construir muralhas - algumas vezes físicas - à globalização da força de trabalho. Não obstante, aquela possi- 
bilidade de impor regulações efetivas ao capital, permitindo-se que, por meio do Estado, sejam conduzidas políticas redistributivas efetivas, simplesmente não existe mais. No limite, se for premido por restrições e regulações, o capital migrará gerando desemprego e falta de legitimidade aos governos nacionais que o queiram controlar.

Tais mudanças na economia associadas à construção - factual e discursiva - de ameaças globais (ambientais, terroristas, bélicas etc.) levam ao deslocamento - até a completa suspensão - da fronteira entre política interna e externa (Beck, 1998). Tornou-se evidente que nenhum Estado Nacional individual pode garantir segurança e bem-estar à sua população, se não puder construir as condições externas, vale dizer internacionais, para a existência desses. ${ }^{3}$

Internamente, os Estados-Nação passam também por transformações profundas. Em primeiro lugar, a pressão homogeneizadora de uma cultura mundial global leva ao aparecimento de movimentos de resistência cultural regionais que, de forma reativa, revivificam e buscam difundir as identidades locais, estabelecendo conexões e relações com o resto do mundo que prescindem da mediação nacional. ${ }^{4}$ Em segundo, os cada vez mais intensos movimentos migratórios do sul para o norte reconfiguram as democracias maduras, confrontando-as, nos casos bem-sucedidos, com uma pluralidade de caráter novo ou realimentando, entre seus membros, nos casos mais problemáticos, regressões nacionalistas e segregacionistas.

Ressalte-se que os movimentos migratórios contemporâneos têm natureza distinta daqueles que levaram ao deslocamento de milhões de europeus para as Américas no período anterior às guerras. Tratava-se, naqueles casos, da interrupção praticamente definitiva dos contatos com o lugar de origem, num contexto em que as políticas de completa assimilação ao país de adoção, seja pela pressão moral, seja pela simples coerção, eram aceitas como legítimas. ${ }^{5}$ Nos dias que correm, há pressões de toda ordem contra a implementação de políticas assimilacionistas e, em muitas sociedades, a valorização da diversidade cultural e o elogio da diferença dão o tom das políticas culturais. Ao mesmo tempo, as novas pos- sibilidades de comunicação e circulação permitem os contatos permanentes dos imigrantes com suas regiões de origem, perdendo a integração social ao país de adoção sua compulsoriedade.

O terceiro fator que favorece a pluralização cultural no interior dos Estados-Nação são as mobilizações sociais transnacionais e os intercâmbios comunicativos entre grupos sociais de diferentes regiões do mundo. O incremento das trocas materiais e simbólicas para além das fronteiras da nação leva à condensação e à difusão de novos estilos de vida e novas visões de mundo, assim como ao descolamento ou à desterritorialização das diversas manifestações culturais de seus loci de origem. Assim, da mesma forma como os jovens da periferia paulistana recriam no Brasil o bip hop, em Moçambique, o incipiente movimento de mulheres procura fazer valer a eqüidade de gênero, em consonância com os direitos conquistados pelas feministas européias ou norte-americanas.

Apresentadas nessa forma muito resumida, é essa ampla reconfiguração das relações econômicas, políticas e sociais que, evidentemente, não tornam o Estado-Nação obsoleto, mas o redefinem funcionalmente, que constitui a base empírica da qual partem os defensores do projeto de uma democracia cosmopolita. É precisamente esse complexo deslocamento das fronteiras da economia, da cultura e da política que originaria o esforço recente de se buscar formas de "governar para além das fronteiras do Estado-Nação", conforme o título sugestivo de Zürn (1998).

Se o diagnóstico de época que os alimenta é, em grande medida, comum, os projetos de democracia cosmopolita já em circulação são, como se afirmou acima, muito variados, incluindo desde o mero fortalecimento dos organismos multilaterais até um translocalismo basista com vistas a criar, a partir da eticidade comunitária, os termos de uma ordem mundial cosmopolita justa.

Roland Roth (2001) coligiu, recentemente, as diferentes contribuições e concepções ao tema da democracia cosmopolita numa classificação preliminar, a qual procura-se reorganizar e completar no Quadro 1, de sorte a oferecer uma idéia aproximativa da diversidade e da multiplicidade dos termos do debate em curso. 
Observe-se que as diferentes correntes e princípios identificados no quadro não são mutuamente excludentes: tanto pode haver instrumentos que se repetem em diversas visões, como combinações, nas formulações de um mesmo autor, de elementos de correntes aqui tratadas como distintas. O sentido do quadro é apenas diferenciar ênfases, razão pela qual se renuncia aqui a uma explicação detalhada de seus termos. Para nossos objetivos, o que parece mais relevante é detalhar aspectos não explicitados dos modelos.

\section{Sociedade civil global: implausível e indesejada}

\section{Sociedade civil na constelação nacional}

O conceito de sociedade civil percorreu uma trajetória teórica e política absolutamente ímpar nos anos recentes. Redescoberto, simultaneamente, ou com pequenas diferenças temporais, em diferentes contextos, o conceito acabou prestandose a objetivos muito diversos, cumprindo em quase todos os casos a promessa política que trazia consigo. Em geral, o conceito pôde, como mostra Dubiel (2001, p. 135), "abarcar uma multi- plicidade de modelos interpretativos, narrativas e expectativas normativas que um marxismo debilitado" não conseguia mais decodificar.

Assim, a polissemia do termo civil permitiu que, a partir do final dos anos de 1970, a sociedade civil se tornasse sinônimo, em países assolados pela guerra (civil, diga-se) na África subsaariana e na América Central, de "algo contrário aos atores da guerra" (Centro de Estudos Africanos, 2002). Em muitos desses casos, a retórica da sociedade civil permitiu juntar inimigos irreconciliáveis em torno dos programas de pacificação (Kurtenbach, 2000).

$\mathrm{Na}$ América do Sul, o termo civil foi tomado como uma oposição a militar, prestando-se de ligadura à aliança que reunia parceiros pouco prováveis, como empresários e sindicalistas, setores da igreja progressista e movimentos de gênero ou movimentos étnicos e nacionalistas de esquerda (Costa, 1997). No Leste Europeu, civil significou não-estatal, nomeando-se com o termo os poucos campos da vida social que se mantinham preservados da influência do Estado socialista onipresente. Aqui, a sociedade civil não ia, portanto, muito além da vida privada e da religião (Cohen e Arato, 1992, pp. 32 ss.).

Nos Estados Unidos, em contrapartida, civil adquiriu, tanto na versão liberal como na visão co-

Quadro 1

\section{Visões da Democracia Cosmopolita ${ }^{6}$}

\begin{tabular}{|c|c|c|}
\hline TIPO & PRINCí́io/Instrumento & REPRESENTANTES \\
\hline GOVERNO MUNDIAL & $\begin{array}{l}\text { Estado mundial federado, no qual } \\
\text { cada um dos Estados nacionais existentes } \\
\text { constitui uma unidade da federação. }\end{array}$ & Otfried Höffe (2002) \\
\hline POLÍTICA INTERNA MUNDIAL & $\begin{array}{l}\text { Ampliação das estruturas de produção da } \\
\text { governança global (regimes, ONGs etc.) } \\
\text { sem governo mundial. }\end{array}$ & $\begin{array}{l}\text { Jürgen Habermas (1998), } \\
\text { Michael Zürn (1998) }\end{array}$ \\
\hline $\begin{array}{l}\text { Internacionalismo } \\
\text { liberal/democrático }\end{array}$ & $\begin{array}{l}\text { Fortalecimendo da ONU e das articulações } \\
\text { entre os Estados nacionais }\end{array}$ & Mark Imber (1997) \\
\hline Comunitarismo Radical & $\begin{array}{l}\text { "Going local": defesa de um "basismo" } \\
\text { associado a um federalismo translocal. }\end{array}$ & Michael Shuman (1998) \\
\hline $\begin{array}{l}\text { "Cidadanismo" } \\
\text { mundial }\end{array}$ & $\begin{array}{l}\text { Institucionalização de um direito cosmopolita, } \\
\text { fundado nos direitos humanos, na sociedade } \\
\text { civil global e na regulação global da economia. }\end{array}$ & $\begin{array}{l}\text { David Held (1995) } \\
\text { Anthony McGrew (1997) }\end{array}$ \\
\hline
\end{tabular}


munitarista, o sentido de virtude pública, nomeando o mínimo de altruísmo necessário para manter a reprodução da ordem liberal num contexto de pluralismo de valores (Walzer, 1991; Shils, 1991). Nas democracias européias, o conceito assumiu uma feição distinta de todas as anteriores. Civil tornou-se oposição a burocrático, desvitalizado, inflexível, características atribuídas ao Estado de bem-estar social, o qual cabia à sociedade civil reformar (Keane, 1988).

No plano analítico, a reconstrução do conceito segue uma lógica igualmente autônoma e descentralizada. Em consonância com os objetivos políticos colimados e a partir do repertório teórico disponível em cada contexto, valeu-se algumas vezes de Hegel e Marx, em outros casos de Tocqueville e Durkheim ou Gramsci e Arendt, para delinear, em cada caso particular, o conceito de sociedade civil que parecesse mais adequado. Só mesmo ao final dos anos de 1980, o conceito ganharia, com o trabalho de Cohen e Arato, uma interpretação hegemônica, que busca dialogar com as diferentes vertentes que haviam procurado reinventá-lo nos anos anteriores. Permita-se aqui relembrar um breve momento da reintepretação feita por esses autores do modelo de dois níveis de sociedade de J. Habermas, já que a passagem é fundamental para o argumento desenvolvido a seguir.

Trata-se da definição proposta por Cohen e Arato, segundo a qual a sociedade civil corresponde à dimensão institucional do mundo da vida (em contraste com sua dimensão lingüístico-simbólica) e abrange, assim, as estruturas "cuja tarefa é preservar e renovar as tradições, as solidariedades e as identidades" (1989, p. 495). Recorde-se, ainda, que Habermas incorpora a definição dos autores a seu modelo discursivo da democracia, atribuindo à sociedade civil um caráter duplo. No plano cultural, a sociedade civil atuaria, conforme Habermas, defensivamente, como locus de formação de uma opinião pública ancorada no mundo da vida. No plano político, caberia à sociedade civil a função ofensiva de, ao lado do direito, atuar como um decodificador que verte as demandas nascidas no cotidiano para a linguagem sistêmica da política institucionalizada.

\section{Sociedade civil worldwide}

Para os democratas cosmopolitas, a sociedade civil global ganha sua plausibilidade empírica a partir da emergência de incontáveis atores não estatais que se encontram em Porto Alegre, Seattle ou Gênova para tratar de questões que não podem ser associadas a uma constelação nacional particular, conforme atestam os casos das reivindicações por uma justiça social global ou pela preservação da biodiversidade. Do ponto de vista das expectativas políticas e normativas, a sociedade civil mundial ocupa, nos variados aportes à democracia cosmopolita, papéis distinto.?

Na versão mais moderada, a função atribuída à sociedade civil se restringe à participação nos fóruns consultivos e deliberativos existentes ou a serem constituídos globalmente, seguindo a lógica da criação de "regimes" internacionais (convenções do clima, biodiversidade, drogas etc.). Os representantes da "sociedade civil mundial" defenderiam, nesses fóruns, interesses e pontos de vista do conjunto da sociedade mundial, em oposição à visão particularista das grandes corporações e mesmo dos Estados nacionais (Vieira, 2001).

Uma versão mais enfática da democracia cosmopolita atribui aos atores da sociedade civil global o poder de imprimir, na política mundial, um impulso democratizante semelhante àquele que as sociedades civis nacionais injetaram em diferentes países. Nessa visão, a sociedade civil mundial costuraria os laços de uma integração societária global num momento em que, sistemicamente, o mundo é, de fato, uno (Habermas, 2001, pp. 17 ss.; Brunkhorst, 2002, pp. 171 ss.).

A importância política das novas formas de mobilização transnacional é indiscutível. Contudo, compará-las às sociedades civis nacionais parece, por várias razões, um procedimento não autorizado. Caso se tome, por exemplo, o mencionado caráter bidimensional da sociedade civil, fica evidente que falta à sociedade civil global a dimensão cultural/defensiva. Falta, ressalte-se, o ancoramento no mundo da vida, aquela caraterística que assegura precisamente o caráter democrático/democratizante da sociedade civil. Ou seja, se deve caber mesmo à sociedade civil manter e reprodu- 
zir o repertório de tradições, solidariedades e identidades no interior da nação, há que se perguntar: quais são, propriamente, as representações e os valores que caberá à sociedade civil global preservar? Afinal, não existe um mundo da vida mundial, a partir do qual situações-problema detectadas por uma sociedade civil global possam ser lançadas a uma esfera pública mundial.

Sociedade civil - assim como esfera pública -, antes de serem categorias da teoria da democracia, são conceitos da história social e se referem, em cada contexto nacional particular, a uma trajetória própria e específica. Como se sabe, as sociedades civis (e as esferas públicas) formam-se no âmbito de processos extremamente complexos que acompanham o aparecimento das nações modernas como "comunidades imaginadas" e são indissociáveis, nesse sentido, do aparecimento das estruturas comunicativas de abrangência nacional (meios de comunicação supralocais, sistema escolar unificado etc.), assim como das grandes narrativas (bélicas, históricas etc.) que culminam com a formação de um público nacional com interesses compartilhados (Costa, 2003a).

Naturalmente, não se verificou nem está se verificando, no âmbito global, um processo semelhante. No lugar de uma sociedade civil global, as mobilizações transnacionais de atores não estatais conformam uma gama variada de redes temáticas fragmentadas. Os problemas aí discutidos não convergem para o estabelecimento de uma comunicação global, envolvendo um público mundial. São tratados, ao contrário, em espaços comunicativos transnacionais segmentados, aos quais só tem acesso aquela elite de militantes internacionalizada.

Discutidas transnacionalmente por um grupo restrito de ativistas, é por meio das estruturas das esferas públicas nacionais que as questões tratadas nesses contextos comunicativos transnacionais ganham repercussão, apresentando em cada país uma lógica nacional própria. Por exemplo, quando, por ocasião de uma conferência de cúpula, determinados temas entram simultaneamente nas agendas de diferentes esferas públicas nacionais, o que se verifica não é um intercâmbio comunicativo entre as populações das diferentes regiões do mundo. Há, nesses casos, uma troca de informações e experiências entre um conjunto reduzido de ativistas políticos que se incumbem então de fazer com que os temas discutidos com os colegas de diferentes países circulem nas respectivas esferas públicas nacionais. A forma, contudo, como tais temas são discutidos internamente em cada país segue uma dinâmica própria, determinada por fatores nacionais, como o nível de articulação dos atores sociais responsáveis pela difusão do tema, o grau de integração internacional da mídia nacional, o interesse do governo nacional em incorporar o tema em questão à sua agenda etc.

O conceito de sociedade civil global é equívoco porque sugere que está se formando uma agenda social a partir das experiências acumuladas nas diferentes regiões do mundo e, mais, que tal agenda permanece submetida ao crivo de uma esfera pública mundial porosa e democrática. Na verdade, a retórica da democracia cosmopolita acaba ocultando a distribuição desigual de chances e de poder que reina na Realpolitik mundial. Como mostra Roth:

O discurso que trata de redes e nós não pode encobrir o fato de que, na cooperação transnacional entre ONGs e mesmo nas ONGs transnacionais, a distribuição de influência, poder, recursos, pessoal e temas apresenta um claro desnível nortesul. [...] Isso vale não apenas para os quadros de pessoal e estruturas de decisão, mas também para a escolha das campanhas, as quais são feitas sob medida para atender o gosto do público generoso da OCDE (2001, p. 9).

Essa passagem responde, de certa maneira, à questão levantada, relativa às tradições, identidades e solidariedades que a suposta sociedade civil mundial deveria preservar. Com efeito, a nova agenda social global decorre, fundamentalmente, das experiências de umas poucas sociedades civis nacionais que dominam o mundo global das ONGs. Assim, o risco sério que corre o programa de uma democracia cosmopolita que tenha sustentação na sociedade civil global é o de buscar difundir, mundialmente, as experiências, as formas de percepção e os valores de uma meia dúzia de sociedades civis específicas. Esse risco abstrato ga- 
nha contornos claros na forma como muitos autores buscam justificar a implementação de uma política mundial de direitos humanos.

\section{A universalidade dos direitos humanos}

Ao declarar, sua guerra incansável ao "eixo do mal", Bush acabou externando, por descuido político, várias das fragilidades teóricas presentes nos aportes à democracia cosmopolita. Sem dúvida, a declaração simbólica de guerra dividia o mundo em duas partes, estabelecendo de saída, como verdade ontológica, a que representava o bem e a que representava o mal. A justificativa para buscar fazer valer o catálogo ocidental de direitos humanos em todas as regiões do mundo, construída pelos teóricos da democracia cosmopolita, mesmo que menos grosseira, não difere, em sua natureza, da perspectiva de Bush. Em ambos os casos, constrói-se uma história teleológica, segundo a qual aquele conjunto de sociedades que se industrializou pioneiramente constitui um bastião de valores, instituições e formas de vida moralmente mais avançados. Nesse raciocínio, não haveria razões para deixar os quatro quintos da população do mundo que vivem nas demais regiões do globo privados de tal iniludível evolução (ver Habermas, 1998; para uma crítica, ver Costa, 2003b).

Em sua discussão com críticos que se opõem à universalização dos direitos humanos em nome da preservação imperativa de particularidades culturais, Habermas leva ao paroxismo tal visão. Segundo o autor:

Hoje as outras culturas e religiões do mundo do mundo estão expostas aos desafios da modernidade societária de forma semelhante àquela que esteve a Europa, em seu devido tempo, quando os direitos humanos e o Estado de direito democrático foram, de certa forma, inventados (1998, p. 181, grifo nosso)

Tratado nesses termos, o catálogo de direitos humanos representaria algo como uma ajuda ao desenvolvimento humanitário dos países pobres, permitindo que esses, valendo-se do exemplo das sociedades mais "avançadas", queimem etapas em seu processo de desenvolvimento moral, encurtando o tempo de sofrimento da população que ainda está privada do acesso aos direitos "universais".

O paralelo entre tal visão e uma teoria da modernização à la Parsons, dominante até os anos de 1970, é inevitável. Como se sabe, essa teoria caracterizava as sociedades localizadas na região do Atlântico Norte como uma espécie de ponto de chegada da história moderna, cabendo reformar as instituições e as estruturas vigentes no "resto" do mundo, à sua imagem e semelhança, de sorte que todos pudessem ter acesso ao progresso material e à racionalidade axiológica supostamente reinantes no hemisfério norte. ${ }^{8}$ No presente, as visões da democracia cosmopolita prescrevem uma reforma ainda mais profunda e uma intervenção ainda mais direta nas regiões "atrasadas": a modernização deve atingir as bases morais de tais sociedades.

$\mathrm{O}$ argumento mais recorrente contra a plausibilidade da universalização dos direitos humanos, nos termos propostos pelos democratas cosmopolitas, provém da corrente "realista", presente no campo disciplinar das relações internacionais (Giesen, 2000). Conforme esses autores, a pauta dos direitos humanos não pode ser separada do jogo real e das relações assimétricas de poder na arena internacional. Em outras palavras, as disputas entre os países configura uma ordem hobbesiana, na qual cada Estado-Nação busca fazer valer seus interesses próprios, recorrendo, se for o caso e por puro oportunismo, à alusão retórica a valores universais. Tratar-se-ia, portanto, de um novo imperialismo cultural que só legitima e faz crescer o poder dos países ricos.

Um argumento realista adicional enfatiza a influência do complexo industrial-militar nas relações internacionais, que faz com que as "intervenções bélicas humanitárias", independentemente de sua real inevitabilidade, sejam apresentadas de quando em quando como inescapáveis (Roth, 2001, p. 7). Ou seja, a suspeita é que a máquina de destruição bélica tem uma dinâmica sistêmica própria e imperativa: não espera razões políticas para ser acionada, ao contrário, põe a política em ação para que esta construa os argumentos que legitimem a condução de mais uma "guerra justa". 
As intervenções bélicas, em nome da defesa dos direitos humanos, desde a Guerra do Golfo em 1991 parecem dar razão aos realistas. Afinal, em todos os casos ocorridos, seja em Kosovo, no Afeganistão ou mais recentemente no Iraque, pode-se identificar, em cada situação particular, a maneira específica pela qual os interesses de grupos e países determinados buscaram abrigo sob o manto da alusão retórica a valores universais. Outro aspecto que ficou evidente em todos os casos é que, no complexo jogo de poder verificado na arena internacional, a defesa dos direitos humanos em uma região fez agravar o desrespeito a outros grupos em outras regiões. Assim, por exemplo, a chamada aliança contra o terror, ao mesmo tempo que libertou o Afeganistão de uma dominação tirânica, implicou, por exemplo, maior liberdade para os russos reprimirem os chechenos ou para o governo norte-americano flexibilizar o respeito aos direitos civis dos imigrantes árabes nos Estados Unidos.

Por último, o risco de que a tese da guerra preventiva postulada pelos Estados Unidos, se transforme em nova doutrina das relações internacionais põe fim à ambigüidade das "intervenções humanitárias" (ver Lindgren Alves, 2002, pp. 110 ss.). Afinal, se num quadro de absoluta assimetria de poder bélico, a potência militar hegemônica logra legitimar o ataque a um país soberano, usando o argumento de que suspeita que tal país representa uma ameaça à segurança interna de quem profere o ataque, já não há mais razões para supor que interesses humanitários ainda desempenhem alguma função nos confrontos internacionais. O que há, nesse caso, são apenas interesses nacionais numa disputa de poder hobbesiana, cujo final é previsível: os mais fortes decidirão o jogo a seu favor.

Há, ainda, restrições de outras naturezas ao argumento dos democratas cosmopolitas, quando defendem estender, globalmente, a validade do catálogo ocidental de direitos humanos. Trata-se, aqui, da descrição da história universal numa linha evolutiva que culminaria com o lugar privilegiado ocupado pelas nações "modernas", como parâmetro de respeito aos direitos humanos.
Ora, ainda que o Giddens ideólogo, eloqüente mas pouco convincente na defesa de seu programa da Terceira Via, insista em desmenti-lo, aprendemos anos atrás com o Giddens, sociólogo preciso e consistente da teoria da estruturação, que o evolucionismo não faz bem às ciências humanas. Naquela ocasião, o autor (Giddens, 1984, pp. 240 ss.) alertava para vários riscos evolucionistas, dos quais pelo menos dois parecem vitimar os teóricos da democracia cosmopolita, e, ironicamente, o próprio Giddens, a saber:

i) Tratar uma seqüência particular de eventos ocorridos numa sociedade determinada como uma lei histórica de transformação.

ii) Confundir a superioridade, em termos de poderio tecnológico, econômico ou bélico com superioridade moral, como se as sociedades mais desenvolvidas tecnologicamente fossem necessariamente mais avançadas moralmente.

Ao estabelecer um paralelo entre a Europa do século XIX e o restante do mundo hoje, supondo que as "outras" sociedades representam um estágio anterior da modernidade, o enfoque da democracia cosmopolita incorre no primeiro erro evolucionista citado. Quando busca estabelecer o catálogo ocidental dos direitos humanos como meta para todos os países do mundo, comete o segundo erro.

O problema analítico, nos dois casos, é que se desconsidera as histórias entrelaçadas (entangled histories, Randeria, 2001) do ocidente e do restante do mundo e, mais do que isso, o caráter meramente contingente dos desenvolvimentos que levaram os países do hemisfério norte a adquirir uma posição privilegiada, recentemente, na defesa dos direitos humanos. Essa posição não é necessariamente definitiva, isto é, não representa um lugar definido numa linha de evolução inelutável e imutável da modernidade, é antes o reflexo momentâneo de um conjunto de injunções políticas.

Não se pode esquecer, por exemplo, que no momento em que "inventava" os direitos humanos e o Estado de direito, a Europa praticava o colonialismo e a escravidão moderna, no outro lado do Atlântico. Foi também no seio da 
ciência iluminista do século XIX que se "inventou" a fundamentação biológica da desigualdade entre as pessoas de características físicas distintas e lançou-se as bases para a legitimação moderna das hierarquias raciais. Lembre-se também que, até finais dos anos de 1940, fontes tão diversas quanto ativistas negros norte-americanos, Unesco e exilados judeus fugidos do nazismo pensavam que o Brasil representava para o mundo um modelo de respeito aos direitos humanos e de estabelecimento de uma igualdade efetiva entre todos os grupos demográficos. ${ }^{9}$

Ou seja, do ponto de vista da história social, a descrição da modernidade como uma trajetória linear, na qual os países tecnologicamente mais avançados do Atlântico Norte representam, por desígnio e pela lógica interna de um ciclo evolutivo, uma certa vanguarda moral do mundo contemporâneo, não tem sustentação nos fatos. Nesse sentido, reivindicar que as sociedades civis e os governos nacionais do Atlântico Norte definam e ponham em vigor um catálogo de direitos humanos de validade ampla é tão plausível quanto foi, no século XIX, pretender que o proletariado se tornasse o ator universal da história moderna. O que se quer dizer é que o argumento de que há uma evolução desigual dos valores iluministas nas diferentes regiões mundo e que, portanto, é legítimo que as regiões mais avançadas em sua consecução prescrevam às demais regiões a trilha a ser seguida é insustentável teórica e historicamente. Definitivamente, tal argumento não serve como fonte de legitimação de um catálogo universal dos direitos humanos.

No raciocínio desenvolvido até aqui, a questão de fundo permanece ainda intocada. Afinal, desconstruir teórica e analiticamente as expectativas dos democratas cosmopolitas não soluciona os problemas político-morais que eles buscam enfrentar, como a necessidade de re-regular a economia, sob a égide da justiça social global, a proteção contra as ameaças globais, a concretização da justiça de gênero, étnica, o combate à violação dos direitos humanos etc. Isto é, parece justo argumentar que, no âmbito da democracia cosmopolita, indica-se a oportunidade política de se estender as conquistas inegáveis efetivadas pelas sociedades civis do norte ao "restante" do mundo e qualquer restrição teórica parece menor diante de uma possibilidade política de tal ordem.

Com efeito, para quem descarta o argumento universalista dos democratas cosmopolitas só restam duas saídas: o cetismo e a capitulação diante de um mundo que "é, mesmo assim, desigual e injusto" ou o ônus de buscar alternativas mais satisfatórias para os problemas enfrentados pelos democratas cosmopolitas. Formulada nesses termos, a primeira possibilidade descredencia como neoconservador quem a tome como alternativa. A segunda é por demais ambiciosa para as limitações deste artigo. Permita-se, assim, que se restrinja aqui à demarcação apenas indicativa de alguns passos necessários para fugir aos equívocos cometidos pelos democratas cosmopolitas.

Em primeiro lugar, há que se desfazer a impressão de que o debate em torno da globalização dos direitos humanos encerra um confronto entre, de um lado, particularistas, presos a valores conservadores, identidades e formas de vida locais fossilizadas e, de outro, universalistas, que defendem valores desarraigados, desenraizados de contextos culturais específicos. Ora, aprendemos com o debate entre liberais e comunitaristas nos anos de 1980 e 1990 que há uma distinção fundamental a ser feita entre princípios de justiça, regulados pelo código binário justo e injusto e concepções de bem, que diferenciam a vida virtuosa da vida indesejada. Os direitos humanos precisam ser tratados como um conjunto abstrato de princípios de justiça que podem (ou não) ganhar concretude nos diferentes contextos culturais. Implicam, por exemplo, eqüidade de gênero, fim da opressão étnica e racial etc., mas não uma forma cultural de vida particular, por meio da qual essas metas foram concretizadas num contexto específico. Essa distinção é fundamental porque afasta a tentação de hierarquizar, num procedimento evolucionista, as diferentes culturas, além de mostrar a necessidade de se compreender a concretização dos direitos humanos, nos termos da gramática moral de uma sociedade particular. Nada aqui deve lembrar a relativização cultural que transforma, por exemplo, o machismo ou o racismo em práticas culturais a serem 
preservadas. Pode-se, por exemplo, reconhecer que os Estados Unidos ou a Suécia fizeram avanços mais significativos do que o Brasil ou o Sudão no sentido de construir a igualdade de oportunidades para negros e brancos, homens e mulheres e, ao mesmo tempo, rejeitar a transposição das relações étnicas e de gênero dos Estados Unidos e da Suécia para o Brasil e o Sudão. Afinal, a maior eqüidade de gênero e étnica encontrada na Suécia ou nos Estados Unidos não é traço imanente das relações de gênero e raciais desses países. O mesmo modelo transposto para outras sociedades pode dificultar e não facilitar as chances de reconhecimento social de mulheres e negros.

Essas diferenciações pavimentam o caminho para um passo adicional, qual seja, mostrar que a diversidade de identidades e formas de vida culturais concretas existentes não constitui um obstáculo, e sim condição de possibilidade para a concretização de uma política global dos direitos humanos.

Cabe aqui uma pequena digressão em torno da articulação percebida por Joas (1997) entre os planos da integração cultural e da integração social que, combinados, determinam os contornos de uma configuração social específica. Para o autor, os diferentes sistemas de valores ou formatos de integração cultural apresentam graus de correspondência bastante variável com um sistema de normas universalmente válidas, constatando-se a existência de formatos de integração cultural particularistas, uma vez que se mostram ineptos para a consideração de pontos de vista universais. As democracias diferenciam-se precisamente por revelarem um alto nível de aproximação entre os valores e as disposições inscritas nos processos de integração cultural e as normas reconhecidas universalmente e corporificadas nas instituições políticas. Contudo,

[...] a idéia de que, para superar o particularismo, a particularidade como tal deve desaparecer desconhece o caráter necessariamente contingente dos valores. Condena-se a si própria a permanecer uma mera moral, rompendo com a atratividade dos valores para declarar a motivação [para a ação] assente unicamente na moral como possível (Joas, 1997, p. 174).
As formulações de Joas representam um argumento mais contra o relativismo cultural, na medida em que permitem identificar sociedades, cujo sistema de valores dificulta a implementação de normas que valham igualmente para todos. Não obstante, servem de alerta para aqueles democratas cosmopolitas que julgam possível implementar, nas diferentes sociedades, um catálogo de regras universais que não apresente articulação com os diversos sistemas particulares de valores. É só na interação com esses sistemas concretos de valores e não a despeito deles que as normas universais podem ganhar legitimação e, mais do que isso, validade efetiva e eficácia. De outra maneira, transformam-se em leis que não "pegam", nossas velhas conhecidas.

\section{Conclusão}

Os diferentes aportes à tese da democracia cosmopolita buscam mostrar a necessidade e a viabilidade de se encontrar formas de governar o mundo para além das fronteiras dos Estados existentes, uma vez que a economia, a política e a cultura se descolaram da moldura territorial do Estado-Nação. Dois componentes, apresentados ora como dados da realidade, ora como desiderato político, aparecem como ingredientes recorrentes de um tal governo global "cosmopolita", a saber, a existência de uma ética universal dos direitos humanos e de uma sociedade civil mundial.

Procurou-se mostrar que os conceitos de sociedade civil mundial e de uma ética universal dos direitos humanos, nos termos formulados pelos democratas cosmopolitas, apresentam dificuldades empíricas e teóricas e acabam legitimando uma hierarquia moral no mundo contemporâneo, segundo a qual, instituições, valores e formas culturais de vida vigentes nas sociedades situadas na região do Atlântico Norte constituem modelos de aplicação geral.

Essas restrições às concepções da democracia cosmopolita não resolvem os problemas políticos e morais que tais aportes buscam enfrentar. Indicou-se, por isso, esquematicamente, pressupostos para uma reflexão acerca das possibilida- 
des de uma legitimação não evolucionista das redes transnacionais de ação coletiva e de um catálogo universal dos direitos humanos.

Trata-se, em primeiro lugar, de desvincular a dimensão política da dimensão cultural das sociedades civis. Nesse caso, as conquistas democráticas obtidas pelos movimentos sociais nos países de industrialização pioneira deixam de estar necessariamente associadas às formas culturais de vida concretas verificadas nesses contextos. O que se quer dizer é que, de um lado, se reconhece que o respeito aos direitos humanos ou a reivindicação por eqüidade étnica, de gênero etc. têm um apelo universal indiscutível. De outro lado, constata-se que a forma particular como se buscou, pioneiramente, fazer valer tais reivindicações em alguns países é necessariamente contingente e intransferível. Portanto, a mesma norma universal pode encontrar formas diversas e particulares de concretização cultural.

A ação das organizações e dos movimentos sociais transnacionais visa, em geral, ao combate ao particularismo de uma ordem social racista, sexista ou opressora das minorias étnicas, sem que isso implique que as relações de gênero, "raciais" ou entre diferentes etnias vigentes nos países em que os movimentos sociais avançaram mais constituam modelos válidos para todas as partes. Nesse sentido preciso, não se trata de uma sociedade civil global, uma vez que não há nem deve haver a reprodução ampliada no restante do mundo dos repertórios de tradições e experiências coletivas presentes no Hemisfério Norte. O que se tem é o apelo em estender para as diversas regiões o esforço de superação dos particularismos, preservando, no melhor dos casos, as particularidades dos contextos regionais diversos.

Dessa maneira, parece possível construir a legitimidade da ação das organizações e dos movimentos sociais transnacionais sem que se recorra à idéia de uma sociedade civil global, seja ela dada como existente, seja sua construção apontada como imperativo moral. Desenraizadas dos contextos culturais concretos em que surgem, as reivindicações por justiça trazidas pelas organizações transnacionais circulam nos fóruns internacionais e retornam, por intermédio dos ativistas, das organizações locais e dos meios de comunicação, aos espaços públicos nacionais. É nessas arenas que tais reivindicações são, por assim dizer, interpeladas em sua aspiração de universalidade, induzindo, localmente, processos de inovação cultural e social.

\section{NOTAS}

1 Deputado democrata-cristão alemão.

2 Zizek (2001, p. 479) diz que a ruptura representada pelo paradigma da modernização reflexiva (ou da segunda modernidade) nos coloca diante de uma situação semelhante àquela representada pela forma como Habermas se distingue de Adorno e Horkheimer. Para Zizek, tal similaridade está assente no fato de que, tanto para Habermas como para Giddens ou Beck, "os problemas, como regimes políticos totalitários ou a chamada alienação da vida moderna, não são, enfim, resultados da dialética própria do projeto da modernidade e do esclarecimento, mas do uso inconseqüente destes". A comparação, ainda que sugestiva, é imprópria, porque o sistema de dois níveis de sociedade, vislumbrado por Habermas, reconhece a força colonizadora da racionalidade instrumental, identificando especificidades no mundo da vida. Ou seja, não recusa, mas aceita a dialética da $A u f$ klärung: é em seus termos que busca alternativas à jaula de ferro. Não há também, em Habermas, uma prescrição prévia de uma forma de vida que os atores sociais "deveriam" desejar como no elogio do self reflexivo de Giddens e Beck, mas o delineamento de um contexto no qual pretensões de validade possam se manifestar e construir sua legitimidade. No marco da segunda modernidade, o pólo negativo da relação dialética desaparece, é positivado, retoricamente: os riscos tornam-se chances e as incertezas, possibilidades de autotransformação das estruturas opressivas.

3 As campanhas eleitorais de 2002, tanto para o Parlamento alemão, como para a presidência no Brasil, trouxeram exemplos incontáveis de que a ruptura da fronteira nacional/internacional tornou-se palpável no cotidiano. No Brasil, para além da objeção maldosa, mas frágil, de que faltava ao candidato do PT um diploma universitário para governar o país, o argumento substantivo para buscar desencorajar o apoio a Lula foi o temor à reação dos "mercados mundiais". Na Alemanha, é consenso de que três te- 
mas decidiram a eleição em favor da coalizão governista de social-democratas e verdes: o desemprego, as enchentes de agosto e a guerra do Iraque. No primeiro caso, o primeiro ministro Schröder conseguiu convencer o eleitorado de que não pôde cumprir sua meta de baixar as taxas de desemprego, em função do grau de integração das economias alemã e mundial. Quanto às enchentes, os verdes se beneficiaram da associação - diga-se tecnicamente duvidosa - entre as tempestades e a mudança do clima global. Finalmente, a garantia de que a Alemanha não participaria de uma guerra ao Iraque rendeu os votos que faltavam à coligação. Um dos slogans da campanha dos verdes, valendo-se da popularidade de seu expoente Joschka Fischer, ministro das Relações Exteriores, indica também como a política interna e externa se confundem. Dizia: "Fischer - aussen Minister, innen grün” [Fischer - ministro do Exterior; no interior, verde].

4 Benhabib (1999, pp. 28 ss.) vê manifesto, na emergência das identidades locais e regionais, o paradoxo entre a integração sistêmica global cada vez maior e o declínio da forma moderna, por excelência, de integração social, qual seja, a pertença nacional construída por meio de instituições, da "invenção" da história nacional, das narrativas bélicas heróicas etc. Leis (2002, p. 199) aponta um outro paradoxo na emergência de novos localismos, regionalismos e nacionalismos. Ele mostra que a defesa teórica destes, quando supõe a existência de um Estado de direito, pode ter um sentido de aprofundamento da democratização. Defender as diferenças culturais, no plano das relações internacionais, contudo, tem, para o autor, o sentido de se mostrar, na prática, a favor de limpezas étnicas e genocídios. O que se procurará mostrar a seguir é que a preservação das diferenças culturais é o único sentido possível para uma política universal de defesa dos direitos humanos.

5 A campanha de nacionalização levada a efeito por Vargas no Brasil e estudada a fundo por autoras como Neide Fiori ou Giralda Seyferth exemplifica como se deu a supressão à força da diversidade cultural, políticas antes legítimas e elogiadas e hoje fora de lugar (ver Costa, 2002, cap. 6).

6 Na classificação de Roth, apenas a última da correntes, aqui denominada "cidadanismo mundial", corresponde ao que chama de democracia cosmopolita. As demais seriam formas de democracia transnacional. Como, no debate, as diferentes denominações confundem-se, optou-se aqui por usar a expressão democracia cosmopolita como conceito "guardachuva", que abriga as diferentes tendências.

$7 \mathrm{Na}$ verdade, a proclamação da sociedade civil global, a partir da segunda metade dos anos de 1990, coincide, no âmbito nacional, com um refluxo da idéia de sociedade civil naqueles países, em que a sociedade civil, como conceito e "contexto de ação" (Rödel, 1992), desempenhara anos antes papel relevante. Como exemplo paradigmático servem os trabalhos sobre a trajetória recente das sociedades civis na América Latina, reunidos por Dagnino (2002), que revelam como a "confluência perversa" entre democratização e crescimento da participação cívica, de um lado, e o ajuste neoliberal, de outro, deixara marcas profundas na história recente das sociedades civis na América Latina.

8 S. Hall (1996) descreve, de forma breve mas impecável, como é construída, histórica e narrativamente, na política e na teoria social, a imagem ideológica do "West" em oposição ao "Rest". Knöbl (2001) atualiza essa discussão ao mostrar que teóricos como Habermas, Giddens e Beck compartilham das mesmas premissas da "velha" teoria da modernização, na medida em que ignoram a multiplicidade de formas assumidas pela modernidade. Trata-se não de uma modernidade, mas de múltiplas modernidades que seguem, em cada região, formas e padrões muito diversos.

9 Terminada a Segunda Guerra Mundial, a Unesco pretendeu reavivar os ânimos do mundo ainda traumatizado, divulgando a bem-sucedida experiência brasileira no combate ao racismo. Esbarrou, como se sabe, nas desigualdades raciais detectadas.(ver Maio, 2000). De forma semelhante, os ativistas afroamericanos chegaram a enviar delegações ao Brasil para conhecer o "paraíso racial" brasileiro (ver Hellwig, 1992, pp. 40 ss.). As palavras do escritor judeualemão Stefan Zweig (1941), comparando o Brasil e a Europa, são também conhecidas e servem aqui de ilustração: "O Brasil tratou o problema racial que está assolando o mundo europeu - e o significado deste experimento me parece exemplar - de uma forma absurdamente singela: simplesmente ignorou sua suposta validade". 


\section{BIBLIOGRAFIA}

BECK, Ulrich. (1998), "Wie wird Demokratie im Zeitalter der Globalisierung möglich?", in U. Beck (org.), Politik der Globalisierung, Frankfurt/M, Suhrkamp.

. (1999), Weltrisikogesellschaft, Ökologische Krise und Technologiepolitik", in U. Beck et. al. (orgs.), Der unscharfe Ort der Politik, Opladen, Leske + Budrich.

BENHABIB, Seyla. (1999), Kulturelle Vielfalt und demokratische Gleichbeit. Frankfurt/M, Fischer.

BRUNKHORST, Hauke. (2002), Solidarität. Von der Bürgerfreundschaft zur globalen Rechtsgenossenschaft. Frankfurt/M, Suhrkamp

CENTRO DE ESTUDOS AFRICANOS. (2002), "Sobre a sociedade civil", in http:/ www.cea.uem.mz/pesquisa

COHEN, Jean L. \& Arato, Andrew. (1989), "Politics and the reconstruction of the concept of civil society", in A. Honneth et al. (orgs.), Zwischenbetrachtungen. Im Prozeß der Aufklärung. Frankfurt/M, Suhrkamp.

. (1992), Civil society and political theory. Cambridge, Cambridge Mit Press.

COSTA, Sérgio. (1997), Dimensionen der Demokratisierung. Frankfurt/M, Vervuert. . (2002), As cores de Ercilia. Belo Horizonte, Editora da UFMG.

. (2003a), "Redes sociais de integração transnacional: problemas conceituais e um estudo de caso”. Política e Sociedade, 2.

. (2003b), "Direitos humanos e anti-racismo no mundo pós-nacional". Novos Estudos Cebrap (no prelo).
DAGNINO, Evelina. (org.). (2002), Sociedade civil e espaços públicos no Brasil. São Paulo, Paz e Terra.

DUBIEL, Helmut. (2001), "Unzivile Geselllschaften”. Soziale Welt, 52.

GIDDENS, Anthony. (1984), The constitution of society: outline of the theory of structuration. Cambridge, Polity Press. . (2000), Runway world: how globalization is reshaping our lives. Nova York/Londres, Routledge.

GIESEN, Klaus-G. (2000), "La constellation postnationale: Habermas et la seconde modernité". Les Temps Modernes, 610.

HABERMAS, Jürgen. (1998), Die postnationale Konstellation. Politische Essays. Frankfurt/M, Suhrkamp. . (2001), Zeit der Übergänge. Frankfurt/M, Suhrkamp.

HALL, Stuart. (1996), "The west and the rest: discourse and power", in Stuart Hall et al. (orgs.), Modernity: an introduction to modern societies. Oxford, Blackwell.

HELD, David. (1995), Democracy and global order. Cambridge, Polity Press.

HELLWIG, David (ed.). (1992), African-American reflections on Brazil's racial paradise. Philadelphia, Temple University.

HÖFFE, Otfried. (2002), Demokratie im Zeitalter der Globalisierung. 1 ed. (ampliada). Munique, C. H. Beck.

IMBER, Mark. (1997), "Geo-governance without democracy? Reforming the UN System", in A. McGrew (org.), The transformation of democracy?, Londres, Polity Press.

JOAS, Hans. (1997), Die Entstebung der Werte. Frankfurt/M, Suhrkamp.

KEANE, John. (1988), Democracy and civil society. Londres, Verso. 
KNÖBL, Wolfgang. (2001), Spielräume der Modernisierung. Das Ende der Eindeutigkeit. Weilerwist, Velbrück.

KURTENBAC, Sabine. (2001), "Zivilgesellschaft und zivile Konfliktregelung. Der Beitrag der Zivilgesellschaft zur Beendigung bewaffneter Konflikte", in P. Henstenberger et al. (orgs.), Zivilgesellschaft in Lateinamerika, Frankfurt/M, Vervuert.

LEIS, Héctor. (2002), "Cidadania e globalização: novos desafios para antigos problemas", in I. Scherer-Warren e J. M. C. Ferreira (orgs.), Transformaçôes sociais e dilemas da globalização, São Paulo, Cortez.

LINDGREN ALVES, J. A. (2002), "O contrário dos direitos humanos". Lua Nova, 55-56.

MAIO, Marcos C. (2000), "O projeto Unesco: ciências sociais e o credo racial brasileiro". Revista da USP, 46.

MCGREW, Anthony. (1997), "Democracy beyond borders? Globalization and the reconstruction of democracy theory and practice", in A. McGrew (org.), The transformation of democracy?, Londres, Polity Press.

RANDERIA, Shalini. (2001), "Zivilgesellschaft in postkolonialer Sicht", in J. Kocka et al., Neues über Zivilgesellschaft. Aus historisch-sozialwissenschaftlichem Blickwinkel, Berlim, WZB, mimeo.
ROTH, Roland. (2001), "Auf dem Weg zur transnationalen Demokratie. Der Beitrag von Protesten, transnationalen sozialen Bewegungen und Nichtregierungsorganisationen". Berlim, manuscrito.

RÖDEL, Ulrich. (1992), "Zivilgesellschaft als Handlungszusammenhang". Mitteilungen des Instituts für Sozialforschung an der J.W. Goethe-Universitt Frankfurt am Main, 1.

SHILS, Edward. (1991), "The virtues of civil society". Government and Opposition, 26 (2).

SHUMAN, Michael. (1998), Going local: greating self-reliant communities in a global age. Nova York, Free Press.

VIEIRA, Liszt. (2001), Argonautas da cidadania: a sociedade civil na globalização. Rio de Janeiro/São Paulo, Record.

WALZER, Michael. (1991), "The idea of civil society". Dissident, primavera.

ZIZEK, Slavoj. (2001), Die Tucke des Subjekts. Frankfurt/M, Suhrkamp.

ZÜRN, Michael. (1998), Regieren jenseits des Nationalstaates. Frankfurt/M, Suhrkamp.

ZWEIG, Stefan. (1941), Ein Land der Zukunft. Stocolmo, Berman-Fischer Verlag. 


\section{DEMOCRACIA COSMOPOLI- COSMOPOLITAN DEMOCRACY: TA: DÉFICITS CONCEITUAIS E CONCEPTUAL DEFICITS AND EQUÍVOCOS POLÍTICOS}

\author{
Sérgio Costa
}

\section{Palavras-Chave}

Democracia cosmopolita; Sociedade civil mundial; Direitos humanos.

Dois componentes apresentados, ora como dado da realidade, ora como desiderato político, constituem o núcleo das teorias da "democracia cosmopolita": o apelo a uma ética universal dos direitos humanos, a evocação de uma sociedade civil global. Procura-se mostrar que, nos termos formulados pelos democratas cosmopolitas, ambas as idéias apóiam-se em pressupostos evolucionistas. Instituições, valores e formas culturais de vida vigentes nas sociedades situadas na região do hemisfério norte acabam por ser tratadas per se como superiores $\mathrm{e}$ como modelos de aplicação geral. Contra tal re-hierarquização do mundo, o artigo nomeia, de maneira indicativa, cuidados necessários para que a cooperação transnacional de atores sociais e a globalização dos direitos humanos contribuam para a superação de particularismos nas diversas regiões, levando em consideração, ao mesmo tempo, as particularidades culturais dos diferentes contextos regionais.
Sergio Costa

Key words

Cosmopolitan democracy; World civil society; Human rights.

Both the appeal to some universal ethics and the evocation of a global civil society constitute the core of the "cosmopolitan democracies" theories, presented as either reality data or political desideratum. The paper aims at showing that in the terms formulated by the cosmopolitan democrats both ideas rely on evolutionist presuppositions. Institutions, values, and cultural ways of life effective on societies situated in the northern hemisphere end up being regarded as both per se superior and models for general application. Against such reorganization of the world, the paper indicatively cites necessary precautions in order to have both the international cooperation of social actors and the globalisation of human rights contribute towards overcoming particularisms in the several regions, taking into consideration, at the same time, the cultural particularities of the different regional contexts.

\section{DÉMOCRATIE COSMOPOLITE: DÉFICITS CONCEPTUELS ET ÉQUIVOQUES POLITIQUES}

Sérgio Costa

Mots-clés

Démocratie cosmopolite ; Société civile mondiale; Droits de l'Homme.

L'appel à une éthique universelle des droits de l'Homme et l'évocation d'une société civile globale sont deux composantes qui constituent le cerne des théories de la "démocratie cosmopolite " et qui sont présentées soit comme une donnée de la réalité, soit comme une aspiration politique. L'article cherche à démontrer que, suivant la formulation des démocrates cosmopolites, les deux approches s'appuient sur des présupposés évolutionnistes. Les institutions, les valeurs et les formes culturelles de vie en vigueur dans les sociétés situées dans l'hémisphère nord finissent par être traitées per se en tant que supérieures et comme modèle d'application général. Contre cette nouvelle hiérarchisation du monde, l'article cite, de forme indicative, les soins nécessaires pour que la coopération transnationale d'acteurs sociaux et la globalisation des droits de l'homme contribuent à surpasser les particularismes dans les diverses régions, tout en considérant les particularités culturelles des différents contextes régionaux. 